\title{
Addition of timolol maleate to routine medical therapy: a clinical trial
}

\author{
REDMOND J. SMITH, S. NAGASUBRAMANIAN, \\ R. WATKINS, AND D. POINOOSAWMY \\ From the Glaucoma Clinic, Moorfields Eye Hospital, City Road, London EC
}

SUMmaRY A double-blind cross-over trial of timolol maleate (Timoptol) while routine medical therapy was continued gave the result that pressure was reduced by $3.22 \mathrm{mmHg}$ as compared to placebo and 5.01 compared to pre-timolol levels in 24 patients. There was also a small $(1.858 \mathrm{mmHg})$ drop in pressure in placebo treated eyes, a small and statistically significant drop in resting pulse rate, 76.67 to $71.39 / \mathrm{min}$, and a small but not statistically significant drop in diastolic blood pressure.

Timolol maleate, a beta adrenergic blocking agent, has been shown to be effective in reducing intraocular pressure in patients with open-angle glaucoma. $^{1-4} \mathrm{~A}$ trial was undertaken to measure the degree of further pressure reduction which timolol maleate (Timoptol) would produce in patients already taking medical therapy. The question of whether any improvement found would afterwards be maintained will be the subject of a further study.

\section{Material and methods}

Twenty-four patients with chronic open-angle glaucoma were selected. They were already on topical medication but not on acetazolamide and had not had previous surgery except for one, No. 18, who had had a right trabeculostomy followed by trabeculectomy 1 year previously. They were on a variety of other medical treatments, the commonest pattern being pilocarpine $4 \% 4$ times daily plus guanethidine $1 \%$ and adrenaline $0.5 \%$ twice daily. Other regimens in use were pilocarpine 4\% 4 times daily plus guanethidine $1 \%$ and adrenaline $0 \cdot 25 \%$ twice daily, and in a few cases pilocarpine alone or guanethidine and adrenaline alone.

The age range of the patients was 22 to 81 years with an average of 63 . Nine were men and 15 were women. Those admitted to the trial had a regular pulse rate of 61 or more and a blood pressure of $120 / 70 \mathrm{mmHg}$ or more. The patients were informed of the nature of the trial and consent was obtained.

Each patient was seen at an initial session and the following data were recorded: name, age, sex, date and time of day, intraocular pressure in each eye,

Correspondence to $\mathrm{Mr}$ Redmond Smith, Moorfields Eye Hospital, City Road, London ECIV 2PD. visual acuity, blood pressure, and pulse rate (resting).

Existing therapy was continued and the hospital pharmacy also issued 2 extra bottles (one containing the drug and the other normal saline), instructing the patient to instil 1 drop in 1 eye from 1 bottle and another in the other eye from the other bottle 10 minutes after the already prescribed drops each morning and evening for 1 week.

The patients were examined at weekly intervals. At the conclusion of the third week the therapy was altered so that drug and saline were now instilled in the opposite eyes and the examinations continued for a further 3 weeks. When all had completed their 6-week course the results were reviewed.

The code as to which eye was receiving timolol and which placebo was held in the pharmacy. Unfortunately patients were probably aware which was timolol and which was placebo, since the timolol was issued in a distinctive bottle. Thus only the observers were unaware of the distribution of drug and placebo during the trial.

\section{Results}

The code by which drug or placebo was issued ensured that in 12 of the 24 patients Timolol would be added first in the right eye whereas in the other 12 it would be added first in the left. The possible combinations were therefore as follows:

Right eyes. Timolol first 3 weeks; placebo second 3 weeks, designated RT1-RP2 (12 eyes of patients $2,3,6,8,9,12,15,16,19,20,23$, and 24). Timolol second 3 weeks; placebo first 3 weeks, designated RT2-RP1 (remaining 12 patients).

Left eyes. Timolol second 3 weeks; placebo first 3 weeks, designated LT2-LP1 (same 12 patients as 
group RT1-RP2 above). Timolol first 3 weeks; placebo second 3 weeks, designated LT1-LP2 (same 12 patients as group RT2-RP1 above).

In each of these categories RT1-RP2 etc. 3 intraocular pressures have been recorded on 12 patients, that is, 36 pressures. In the analysis of results, therefore, the figure given for each category is the mean of these 36 readings. In addition the pressure found at the initial examination has been recorded and is expressed as the pretreatment pressure. The mean for each group of 12 eyes is listed; for example, in the group RT1-RP2 the pretreatment figure RT1 (pretreatment) is the mean of all pretreatment pressures for those 12 eyes.

Comparisons can now be made as follows: timolol treated pressures can be compared with pretreatment pressures, for example, RT1-RT1 (pretreatment), or with placebo pressures in the same eyes, for example, RT1-RP2. Results are shown in Table 1.

It will be seen from the table that in each group timolol pressures were lower than placebo pressures by an amount which was statistically significant except in the group LT1. The differences from pretreatment at $-3.89 \mathrm{mmHg}$ or from placebo at $-4.36 \mathrm{mmHg}$, though large, fail to achieve significance because of 1 patient who showed bizarre readings in the left eye, where pressures varied between 24 and 64 during the trial period.

The pooled results expressed as All T-All $P$ show a difference of $-3.22 \mathrm{mmHg}$. In other words, the addition of timolol appeared to be associated with a lowering of pressure of $3.22 \mathrm{mmHg}$ in the 48 eyes of 24 patients. Timolol pressures are also lower than the pretreatment pressures by an amount greater than the T-P result, namely -5.01 .

The comparison of placebo pressures with pretreatment pressures can also be made, and in 2 cases (LP1-LP1 (pretreatment) and RP2-RP2 (pretreatment)) the differences exceed -3.00 and are statistically significant. If the total mean drop in placebo eyes compared to pretreatment eyes is examined it comes to $-1 \cdot 858$, and this difference is statistically significant at the $5 \%$ level.

The effect of timolol in this study does not appear to be related to the initial intraocular pressure, since there is no correlation between the mean pressure drop in the 2 eyes in each patient and the pre-timolol pressure. Similarly, there seems to be no correlation between the pressure drop obtained in each patient and the type of treatment being used initially: for example, pilocarpine $4 \%$, guanethidine $1 \%$ and adrenaline $0.5 \%$, or pilocarpine alone or guanethidine and adrenaline alone.

The mean diastolic blood pressure of the patients before timolol was $92.25 \mathrm{mmHg}$ and the mean of
Table 1 Intraocular pressure

\begin{tabular}{|c|c|c|c|}
\hline & $\begin{array}{l}\begin{array}{l}\text { Average } \\
\text { pressures } \\
(\mathrm{mmHg})\end{array}\end{array}$ & Difference & $\begin{array}{l}\text { Significance } \\
\text { (Student's } \mathbf{t}) \\
\mathbf{P}<\end{array}$ \\
\hline \multicolumn{4}{|l|}{ Right eyes } \\
\hline RT1-RT1 (pretreatment) & $19 \cdot 97-25 \cdot 75$ & $-5 \cdot 78$ & 0.001 \\
\hline RT1-RP2 & $19.97-22.55$ & $-2 \cdot 58$ & 0.01 \\
\hline RT2-RT2 (pretreatment) & $20 \cdot 69-25 \cdot 00$ & $-4 \cdot 31$ & $0 \cdot 1$ \\
\hline RT2-RP1 & $20 \cdot 69-24 \cdot 37$ & $-3 \cdot 64$ & 0.01 \\
\hline RP1-RP1 (pretreatment) & $24 \cdot 33-25 \cdot 00$ & -0.67 & 0.7 \\
\hline RP2-RP2 (pretreatment) & $22 \cdot 55-25 \cdot 75$ & $-3 \cdot 20$ & 0.02 \\
\hline \multicolumn{4}{|l|}{ Left eyes } \\
\hline LT1-LT1 (pretreatment) & $19 \cdot 86-23 \cdot 75$ & $-3 \cdot 89$ & $0 \cdot 1$ \\
\hline LT1-LP2 & $19 \cdot 86-24 \cdot 22$ & $-4 \cdot 36$ & $0 \cdot 1$ \\
\hline LT2-LT2 (pretreatment) & $18 \cdot 10-24 \cdot 41$ & $-6 \cdot 31$ & 0.001 \\
\hline LT2-LP1 & $18 \cdot 10-20 \cdot 69$ & -2.59 & 0.05 \\
\hline LP1-LP1 (pretreatment) & $20 \cdot 69-24 \cdot 41$ & $-3 \cdot 72$ & 0.01 \\
\hline LP2-LP2 (pretreatment) & $24 \cdot 22-23 \cdot 75$ & +0.47 & 0.9 \\
\hline ALL T-ALL P & $19 \cdot 65-22 \cdot 87$ & $-3 \cdot 22$ & 0.001 \\
\hline$\underset{\text { (pretreatment) }}{\text { ALL T-ALL T }}$ & $19 \cdot 67-24 \cdot 68$ & $-5 \cdot 01$ & 0.001 \\
\hline$\underset{\text { (pretreatment) }}{\text { ALL P-ALL P }}$ & $22 \cdot 87-24 \cdot 73$ & $-1 \cdot 86$ & 0.05 \\
\hline
\end{tabular}

Table 2 Diastolic blood pressure

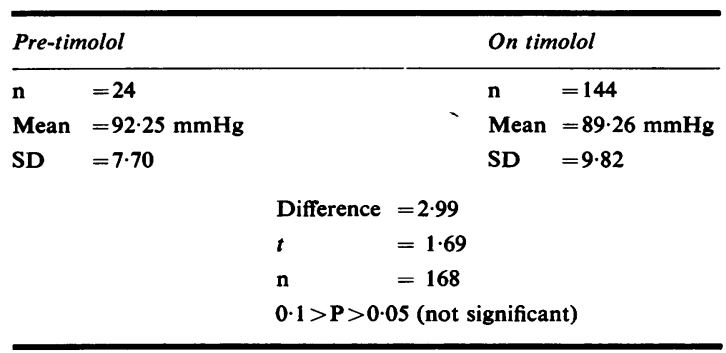

Table 3 Resting pulse rate

\begin{tabular}{|c|c|c|c|c|c|}
\hline \multicolumn{2}{|c|}{ Pre-timolol } & & & \multicolumn{2}{|c|}{ On timolol } \\
\hline $\mathrm{n}$ & $=24$ & & & n & $=144$ \\
\hline Mean & $=76.67$ & & & Mean & $=71 \cdot 39$ \\
\hline \multirow[t]{5}{*}{ SD } & $=8.62$ & & & SD & $=8 \cdot 77$ \\
\hline & & Difference & $=5.28$ & & \\
\hline & & $t$ & $=2.77$ & & \\
\hline & & & $=168$ & & \\
\hline & & $\mathrm{P}<0.01$ & ignificant) & & \\
\hline
\end{tabular}

the 144 readings ( 6 readings on each of the 24 patients) while on timolol was $89 \cdot 26$. The difference failed to achieve significance (Table 2).

The mean resting pulse rate dropped from $76.67 / \mathrm{min}$ before timolol to 71.39 during treatment. The difference was statistically significant $(P<0.01)$. 


\section{Discussion}

The table of pressure readings in eyes receiving timolol maleate (Timoptol) or placebo first or second and the pressure readings in the same eyes before treatment, as previously described, enable the conclusion to be drawn that the addition of timolol to existing treatment appears to be associated with a drop in pressure during the 3-week period of approximately $3 \mathrm{mmHg}$. This is in close accord with the findings of Keates, ${ }^{5}$ who has carried out a very similar study. His difference was expressed in percentage terms as $15 \%$; our result expressed in the same terms would be approximately $15 \%$.

As described above, this pressure drop varies somewhat. For example, it is as high as $6.31 \mathrm{mmHg}$ in left eyes on timolol for the second 3-week period compared to their pretreatment pressure and as low as $2.58 \mathrm{mmHg}$ in right eyes on timolol first as compared with the same eyes on placebo 3 weeks later.

The average for all the timolol versus placebo eyes is -3.22 in favour of timolol, and the average for all timolol pressures versus all pretreatment pressures is -5.01 in favour of timolol.

This is a short-term study which was designed to give a preliminary idea in as short a time as possible of what could be expected from this new drug when added to existing treatment. The trial tells us nothing of the relative merits of timolol maleate versus any other form of treatment nor does it tell us whether the timolol effect is likely to be maintained in the long-term.

It is interesting that a small but statistically significant drop in pressure occurred in the placebo eyes. It is not possible to say whether this is due to observational error, patient error (since the patients were unfortunately able to identify the drug), or to a genuine pharmacological effect, possibly of a systemic nature.
Side effects of the drug were not striking. One patient complained of misty vision in one eye at one visit, but when the code was broken this proved to be the eye taking placebo. Another patient gave up timolol soon after completion of the trial for symptoms of discomfort and headache, and 1 patient complained of mild stinging from the timolol. There were no other definite complaints.

Pulse rates were significantly slowed from a mean of 76.67 to $71.39 / \mathrm{min}$, and diastolic blood pressure was lowered from 92.25 to $89.26 \mathrm{mmHg}$, a drop of $3 \mathrm{mmHg}$, which was not statistically significant.

One rather disconcerting event has to be recorded. The first patient in the trial, a 72-year-old male, died suddenly in the third week of the trial. None of his results are used in the statistics and his place was filled by another patient. The cause of death was given as myocardial ischaemia and fibrosis due to atheroma. The patient's blood pressure was recorded as $170 / 100,160 / 98$, and $162 / 100 \mathrm{mmHg}$ and his pulse rate as 72,74 , and $72 / \mathrm{min}$ at the preliminary examination and at the first and second weekly visits of the trial.

\section{References}

1 Zimmerman TJ, Kaufman HE. Timolol: a beta adrenergic blocking agent for the treatment of glaucoma. Arch Ophthalmol 1971; 95 : 601-4.

2 Zimmerman TJ, Kaufman HE. Timolol: dose response and duration of action. Arch Ophthalmol 1977; 95: 605-7.

3 Radius RL, Diamond GR, Pollack IP, Langham ME. Timolol: a new drug for management of chronic simple glaucoma. Arch Ophthalmol 1978; 96: 1003-8.

4 Nielsen NV. Timolol: hypotensive effect, used alone and in combination for treatment of increased intraocular pressure. Acta Ophthalmol (Kbh) 1978; 56: 504-9.

5 Keates FU. Evaluation of timolol maleate combination therapy in chronic open-angle glaucoma. Am J Ophthalmol 1979; 38: 565-71. 